\title{
The Arden grating test of visual function: a preliminary study of its practicability and application in a rural community in north-west Iran
}

\author{
DARWIN C. MINASSIAN 1 , BARRIE R. JONES ${ }^{1}$, AND AHAD ZARGARIZADEH \\ From the ${ }^{1}$ Department of Clinical Ophthalmology, Institute of Ophthalmology, Moorfields Eye Hospital, \\ London, ${ }^{2}$ Health Sciences Cluster, Bu-Ali Sina University, Hamadan, Iran
}

SUMMARY In a preliminary study involving 75 normal and 10 abnormal eyes the Arden grating acuity test was assessed under difficult conditions of rural field work. It was found to be adequately sensitive and specific for screening out individuals with visual impairment due to refractive errors or ocular disease, and to distinguish between these. Inexperienced paramedical personnel could carry out the test satisfactorily with no difficulty and with a minimum of training. In spite of the unusually distracting conditions under which the test was carried out $95 \%$ of the subjects tested performed satisfactorily. The results of this preliminary study suggest that the Arden grating test is a valuable tool for screening large populations in rural areas of developing countries.

Population-based surveys to determine the prevalence of visual loss from various ocular diseases, and to identify individuals in need of ophthalmic care for remediable blinding eye disease, are important aspects of projects aimed at 'prevention of blindness'.*

Our experience in rural communities of developing countries has shown that screening techniques carried out by trained ophthalmologists, though reliable, are impracticable for large programmes. The need for simple, reliable, and rapid screening methods that can identify and classify visual defects has prompted continuing efforts to develop field techniques which can be used by paramedical personnel with minimal training.

A promising new development, the Arden grating test, has been shown to be a reliable and rapid tool for screening out patients with visual impairment due to refractive errors and ocular disease (Arden, 1978; Arden and Jacobson, 1978; Arden and Gucukoglu, 1978). The purpose of this preliminary study was to assess the practicability of the grating test under difficult conditions of field work in a rural community in north-west Iran.

*Definition: 'Organised, systematic population-based action to prevent blindness'.

Address for reprints: Dr D. Minassian, Department of Clinical Ophthalmology, Institute of Ophthalmology, Judd Street, London WC1H 9QS

\section{Subjects and method}

Persons aged 11 and older were tested during a trachoma survey of a village community at Salouk in north-west Iran. The tests were carried out by an ophthalmologist and in a number of cases by two paramedical personnel who had been previously instructed for about 20 minutes. The illumination used was daylight through an open window. Plates 3 and 5 of the Arden grating test were used according to the procedure described (Arden, 1978). In addition each test was repeated until 2 consecutive identical scale readings were obtained on plate 3 . The number of repeats and the time taken for completion of the test were recorded.

The tests were carried out under difficult conditions in a moderately-sized classroom filled with noisy children and adults who were going through a series of procedures including examination by slit-lamp biomicroscopes and photography of the eyes, conjunctival swabbing, and collection of tears and blood. Dust and flies were additional distracting factors.

\section{Results}

Forty-three patients whose age and sex distribution is shown in Table 1 and Fig. 1 were tested. The youngest was 11 and the oldest 70 years old.

The time taken for explaining the procedure and 
Table 1 Age and sex distribution of patients tested with the Arden grating

\begin{tabular}{lccc}
\hline Age & Malc & Female & Total \\
\hline$\leqslant 10$ & 0 & 0 & 0 \\
$11-14$ & 3 & 1 & 4 \\
$15-19$ & 2 & 6 & 8 \\
$20-35$ & 1 & 9 & 10 \\
$36-45$ & 6 & 3 & 9 \\
$46-55$ & 4 & 4 & 8 \\
$56-65$ & 2 & 0 & 2 \\
$66-70$ & 1 & 1 & 2 \\
$>70$ & 0 & 0 & 0 \\
Total & 19 & 24 & 43 \\
\hline
\end{tabular}

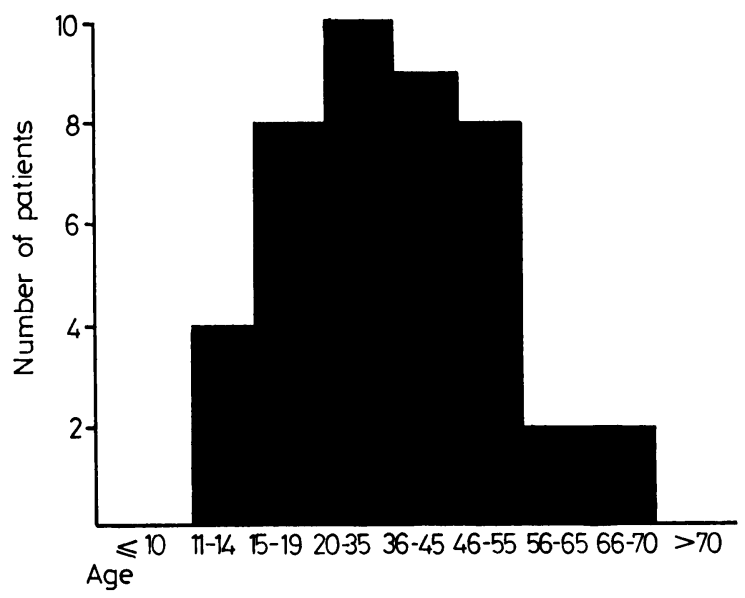

Fig. 1 Age distribution of patients tested with the Arden grating

requirements of the test to each patient and completing the test varied from 3 to 8 minutes according to the number of times the test was repeated. However, the mean time of 4.9 minutes with standard deviation of 1.5 was acceptably short (Table 2).

The number of times each test was repeated for plate 3 varied from 1 to 5 . In 26 subjects $(60 \%)$ the test was repeated once or twice (Fig. 2).

The results of testing 75 normal eyes are shown in Table 2. The mean scale reading obtained from both plates 3 and 5 were relatively low at 10.39 and 10.70 respectively and were well within the normal range of $\leqslant 16$ with $2 \times$ standard deviations added. These results compare favourably with the ones obtained by the experienced observer in Arden's study of normal subjects (Arden, 1978). The results obtained by the 2 paramedical personnel who tested 20 normal eyes were similar to each other and to the result obtained by the ophthalmologist. At most they varied by 2 scale divisions, usually higher than that obtained by the ophthalmologist. Seven persons

Table 2 The Arden grating test: scale readings from 75 normal eyes*

\begin{tabular}{lllll}
\hline & No. of eyes & $\begin{array}{l}\text { Mean scale } \\
\text { reading }\end{array}$ & $\begin{array}{l}\text { Standard } \\
\text { deviation }\end{array}$ & Mean +2 SD \\
\hline Plate 3 & 75 & 10.39 & 1.93 & 14.25 \\
Plate 5 & 75 & 10.70 & 2.1 & 14.9 \\
Total & & 10.55 & 2.03 & 14.61 \\
Time† (minutes) & 4.9 & 1.5 & 7.9 \\
\hline
\end{tabular}

*Eyes were considered to be 'normal' when the following criteria applied: (1) Examination of refractive media by slit-lamp biomicroscope showed no appreciable disease; (2) subject did not complain of visual impairment or any difficulty with near or distant vision.

+ Time taken to explain the requirements and procedure to each patient and to complete the test.

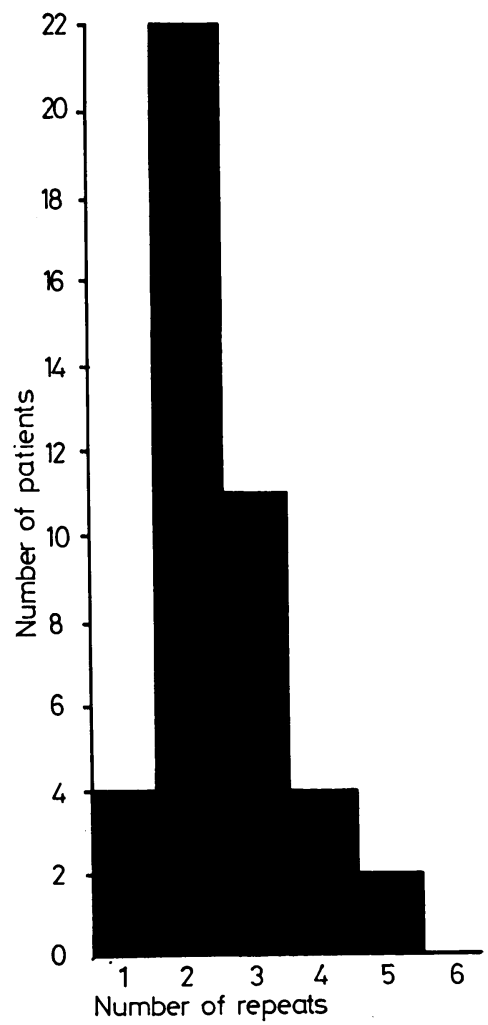

Fig. 2 Distribution of patients according to number of repetitions of the Arden grating test required to obtain two consecutive identical scale readings on plate 3 
Table 3 The Arden grating test: scale readings from 10 abnormal eyes

\begin{tabular}{|c|c|c|c|c|c|c|c|}
\hline Age & Sex & $\begin{array}{l}\text { Plate } \\
R \quad L\end{array}$ & & $\begin{array}{l}\text { Plate } \\
R \quad L\end{array}$ & & $\begin{array}{l}\text { Time } \\
(\min )\end{array}$ & Nature of abnormality \\
\hline 40 & $\mathbf{F}$ & (11) & 11 & (11) & 14 & 5 & Corrected myopic \\
\hline 18 & $\mathbf{F}$ & 10 & (10) & 20 & (10) & 4 & Right eye myopic \\
\hline 33 & $\mathbf{M}$ & (10) & 11 & (14) & 20 & 4 & Left eye myopic \\
\hline 66 & $\mathbf{F}$ & 19 & $>20$ & $>20$ & $>20$ & 3 & $\begin{array}{l}\text { Bilateral cataracts } \\
\quad \mathbf{R}<\mathbf{L}\end{array}$ \\
\hline 60 & $\mathbf{M}$ & 15 & 15 & 20 & 20 & 6 & $\begin{array}{l}\text { Bilateral cataracts } \\
\quad \text { (early) }\end{array}$ \\
\hline 70 & $\mathbf{M}$ & $>20$ & $>20$ & $>20$ & $>20$ & 3 & $\begin{array}{l}\text { Bilateral advanced } \\
\text { cataracts }\end{array}$ \\
\hline 55 & $\mathbf{F}$ & (12) & $>20$ & (9) & $>20$ & 3 & $\begin{array}{l}\text { Left central corneal } \\
\text { scarring }\end{array}$ \\
\hline
\end{tabular}

()$=$ Normal eye.

with 10 'abnormal' eyes were identified by the test. The details, including the nature of abnormality, are shown in Table 3. In 9 out of 10 abnormal eyes the scale reading was well outside the normal for plates 3 or 5 according to the nature of abnormality. The remaining 1 eye with normal scale reading was myopic but the patient was wearing a correction.

Two women aged 27 and 31 failed to perform the test. Both had normal eyes.

\section{Discussion}

The results of this preliminary study suggest that the Arden grating test is a valuable tool for screening large rural populations with very simple resources. The inexperienced paramedical personnel had no difficulty in applying the test satisfactorily after only a very short period of instruction and practice. The illiterate subjects, who were unaccustomed to any type of graphic 'quiz games', were equally quick to grasp the requirements of the test, and, as the results show, they performed satisfactorily.

In view of the distracting conditions it was not surprising that 2 mothers failed to perform the test. Both had young children who had been upset, having gone through the procedure of the trachoma survey, and were a constant source of distraction. The conditions in practice would seldom be as unfavourable and the failure rate would probably be much lower.
The test appeared to be adequately sensitive and specific in screening out people with visual impairment due to ocular disease. It was particularly interesting to note that 4 eyes with refractive errors ( 2 myopic and 2 early cataracts) performed normally on plate 3 but were obviously abnormal by plate 5 readings. By contrast, 5 eyes with visual impairment due to advanced cataract or corneal scarring showed grossly abnormal scale reading on both plates 3 and 5 . This apparent ability of the grating test to discriminate between poor vision which can be corrected by glasses and that which can not and therefore needs further investigation and possibly treatment, is of obvious importance. Another substantial advantage of the grating test over other optotypes lies in its ability to detect loss of contrast sensitivity in presence of normal visual acuity. This ocular state occurs in a number of diseases including chronic open-angle glaucoma. In a recent study Arden and Jacobson (1978) have shown that the grating test is a sensitive and rapid means of detecting neuroretinal damage due to glaucoma with or without optotype visual acuity disturbance.

In view of the encouraging results of this preliminary study and other recent work already referred to, it is recommended that the Arden grating test should be used extensively in population-based surveys to determine the type, prevalence, and distribution of blindness and visual loss in rural communities of developing countries.

It is a pleasure to acknowledge the organisation provided by Professor F. Amini, Vice-Chancellor of Bu-Ali Sina University, Health Sciences Cluster, and the arrangements made by Dr Parsa, Ministry of Health and Social Welfare, Hamadan. Mrs Z. Hajialiakbari and Mr R. Mascan assisted in this work and carried out some of the tests.

\section{References}

Arden, G. B., and Jacobson, J. (1978). A simple grating test for contrast sensitivity: preliminary results indicate value for screening in glaucoma. Investigative Ophthalmology (in press).

Arden, G. B., and Gucukoglu, A. G. (1978). Grating in retrobulbar neuritis: a simple clinical test of contrast sensitivity demonstrates unsuspected visual losses in patients with minimal demyelinisation of the optic nerve. Archives of Ophthalmology (in press).

Arden, G. B. (1978). The importance of measuring contrast sensitivity in cases of visual disturbance. British Journal of Ophthalmology, 62, 198-209. 